\title{
Designing a risk-based surveillance program for Mycobacterium avium ssp. paratuberculosis in Norwegian dairy herds using multivariate statistical process control analysis
}

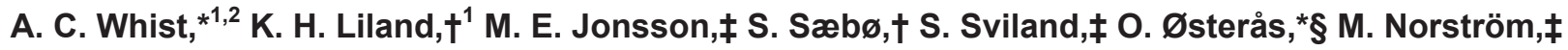 \\ and P. Hopp $¥$ \\ *Department of Production Animal Clinical Sciences, Faculty of Veterinary Medicine and Biosciences, Norwegian University of Life Sciences, \\ PO Box 5003, NO-1432 Ås, Norway \\ †Department of Chemistry, Biotechnology and Food Science, Norwegian University of Life Sciences, PO Box 5003, NO-1432 Ås, Norway \\ ‡Norwegian Veterinary Institute, PO Box 750 Sentrum, NO-0106 Oslo, Norway \\ $\S N o r w e g i a n$ Cattle Health Services, Tine SA, the Norwegian Dairies, PO Box 58, NO-1431 Ås, Norway
}

\section{ABSTRACT}

Surveillance programs for animal diseases are critical to early disease detection and risk estimation and to documenting a population's disease status at a given time. The aim of this study was to describe a risk-based surveillance program for detecting Mycobacterium avium ssp. paratuberculosis (MAP) infection in Norwegian dairy cattle. The included risk factors for detecting MAP were purchase of cattle, combined cattle and goat farming, and location of the cattle farm in counties containing goats with MAP. The risk indicators included production data [culling of animals $>3$ yr of age, carcass conformation of animals $>3$ yr of age, milk production decrease in older lactating cows (lactations 3, 4, and $5)$ ], and clinical data (diarrhea, enteritis, or both, in animals $>3$ yr of age). Except for combined cattle and goat farming and cattle farm location, all data were collected at the cow level and summarized at the herd level. Predefined risk factors and risk indicators were extracted from different national databases and combined in a multivariate statistical process control to obtain a risk assessment for each herd. The ordinary Hotelling's $T^{2}$ statistic was applied as a multivariate, standardized measure of difference between the current observed state and the average state of the risk factors for a given herd. To make the analysis more robust and adapt it to the slowly developing nature of MAP, monthly risk calculations were based on data accumulated during a 24-mo period. Monitoring of these variables was performed to identify outliers that may indicate deviance in one or more of the underlying processes. The highest-ranked herds were scattered all over Norway and clustered in high-density dairy cattle farm

\footnotetext{
Received March 15, 2013.

Accepted June 11, 2014.

${ }^{1}$ These authors contributed equally to this paper.
}

${ }^{2}$ Corresponding author: anne.cathrine.whist@tine.no areas. The resulting rankings of herds are being used in the national surveillance program for MAP in 2014 to increase the sensitivity of the ongoing surveillance program in which 5 fecal samples for bacteriological examination are collected from 25 dairy herds. The use of multivariate statistical process control for selection of herds will be beneficial when a diagnostic test suitable for mass screening is available and validated on the Norwegian cattle population, thus making it possible to increase the number of sampled herds.

Key words: risk-based surveillance, Mycobacterium avium ssp. paratuberculosis, multivariate statistical process control, cattle

\section{INTRODUCTION}

Surveillance programs for animal infections are designed for early detection of emerging infections in a population, to document that a population is free from a variety of infections, or to estimate the prevalence of an infection in a population. The veterinary field faces challenges in developing surveillance programs for rare or low-prevalence infections because such diseases are rarely homogeneously distributed within a susceptible livestock population (Hadorn and Stärk, 2008). Random sampling implies choosing in a way that each unit has the same chance of being selected (Thrusfield, 2005). However, at the population level, in terms of detecting rare diseases, this type of data collection is limited in terms of financial and operational feasibility because a larger sample size is required with a lower prevalence in a specific population (Salman, 2003). Nonrandom sampling is therefore more efficient in detecting rare diseases. Cameron (2012) proposed that if an infection is present, the highest sensitivity of surveillance is obtained by focusing on units that are most likely to be infected. In a risk-based surveillance program, the population is divided into strata based on factors that 
can affect the outcome (risk indicators). Designing surveillance programs so that samples are collected from the strata having higher probabilities of being infected or acquiring the infection may increase the probability of disease detection or decrease the required sample size without reducing the probability of disease detection (Martin et al., 2007). The success of such a program depends partly on proper risk indicator selection, which should be based on scientific knowledge and on properties of the data sources, such as coverage, timeliness, availability, and quality of data.

In Norway, Mycobacterium avium ssp. paratuberculosis (MAP) infection in ruminants is a notifiable disease. In 1996, a national surveillance and control program for bovine MAP was implemented in Norway. During the first $2 \mathrm{yr}$ of the program, samples from imported cattle and from cattle that had been in contact with imported cattle were examined by serology, histopathology, or bacteriological cultures from fecal samples or organs. In 1998 and 1999, the program was expanded to include Norwegian cattle that had no contact with imported animals. Initially, serological examinations were used to screen the herds, and on average, about $8 \%$ of the animals tested were identified as seropositive. However, a follow-up study of these seropositive cattle showed that the reactions were false positives, probably caused by environmental mycobacteria (Fredriksen et al., 2004). Paisley et al. (2000) simulated a surveillance program for bovine MAP in Norwegian dairy herds assuming a prevalence of $0.2 \%$. They concluded that a randomized national survey using serological examinations would be advisable because of the low probability of detecting infected herds and the high number of falsepositive reactions that would be expected. In Norway, herds that are suspected of or diagnosed with MAP are placed under strict restrictions regarding animal movement, sales, shared pasture, and manure deposit. False-positive reactions arising from low specificity of the serological examinations, eventually followed by a long period to confirm or reject the diagnosis, could cause extreme hardship to many dairy farmers. Given the cost of false-seropositive cattle, the current national surveillance program for MAP in cattle relies on bacteriological examination of fecal samples. Fecal samples are collected from the 5 oldest cows in 50 randomly selected herds from a total of approximately 15,000 dairy and beef herds.

A risk-based surveillance program has been developed for MAP to increase the sensitivity of the surveillance. Thus, the aim of this paper was to describe the risk-based selection of herds for the MAP surveillance program in dairy cattle herds in Norway by applying multivariate statistical process control (MSPC; Hotelling, 1947). In MSPC analyses, several variables are combined in a training data set to establish a normal range in which the process is assumed to be in control. Afterward, monitoring of these variables is performed to identify outliers that may indicate deviance in one or more of the underlying processes, suggesting that a unit (herd) should be flagged for further inspection, and to assess whether the herd should be incorporated in the national surveillance program for MAP.

\section{MATERIALS AND METHODS}

The target population for the surveillance program was the dairy cattle population in Norway. The study population included dairy herds in the Norwegian Dairy Herd Recording System (NDHRS; Tine SA, the Norwegian Dairies, Ås, Norway). The study period spanned January 1, 2002, to December 31, 2011, and included 95.3 to $98.3 \%$ of dairy herds in Norway (Tine Rådgiving, 2011). The analyzed data covered a 10-yr time period to evaluate how different risk indicators changed over time and to determine the time intervals over which these indicators should be aggregated.

\section{Data Sources}

The NDHRS comprises data on each cow, including age, origin, calving dates, number of calves, milk production, disease records, movements to or from the herd (purchase and culling), and slaughter information (Figure 1). Milk production and quality are monitored and recorded monthly or every second month. Data reporting is mandatory for members, and data are reported directly or indirectly to the NDHRS database by the farmer, veterinary practitioner, or abattoir or field personnel from the dairy or meat industry (Figure 1). Since 1975, disease cases have been recorded on individual cow health cards, which have been reported to the NDHRS (Solbu, 1983). The Carcasses Database (Animalia, the Norwegian Meat and Poultry Research Centre, Oslo) also transfers data from the slaughterhouses directly into the NDHRS.

The Register of Production Subsidies (Norwegian Agricultural Authority, Oslo) collects information on the number of animals distributed, including species and production type for all holdings that apply for production subsidies. All dairy cattle and dairy goat farmers in Norway are entitled to production subsidies, and the amount is based on the number of animals. The register includes more than $99.7 \%$ of the dairy cattle and goat herds in Norway; for the present study, all cattle and goat herds were extracted from this register.

The Norwegian Goat Health Service (Tine SA, the Norwegian Dairies) comprises data on each goat, including age, origin, milk production, and disease re- 


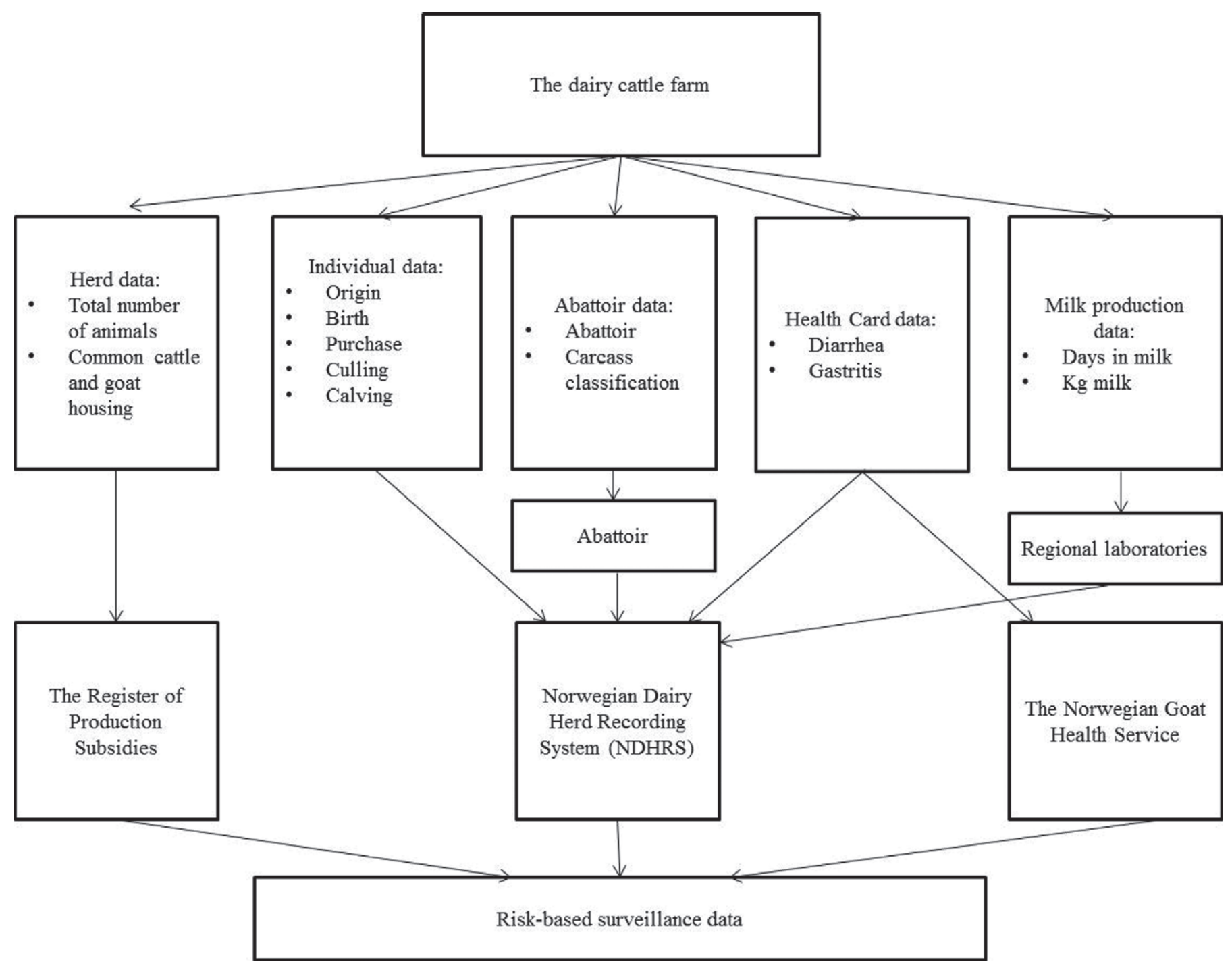

Figure 1. Data sources used in the risk-based surveillance system for Mycobacterium avium ssp. paratuberculosis (MAP) in the Norwegian dairy cattle population.

cords. Data from the Norwegian Goat Health Services database were obtained to identify counties with mandatory MAP vaccination strategies in goats.

\section{Risk Factors}

Since 1996, all MAP infections among cattle in Norway have been attributed to import of infected cattle or subsequent purchase from importing herds (7 cattle herds) or contact with infected goat herds (3 cattle herds); therefore, cattle purchase and proximity to MAP-infected goat flocks were considered as risk factors. Caprine MAP was once endemic in parts of Norway (Kampen et al., 2010), and a national surveillance and control program for MAP in goats and sheep was implemented in 2001 and 2002, respectively. In the surveillance program, both vaccinated and unvaccinated goat herds have been randomly selected for sampling by fecal samples from the 10 oldest goats or, if present, from diseased goats. Sheep herds have been included in the program both randomly and if they are geographically located close to MAP-infected goat herds. Fecal samples are collected from the 10 oldest sheep. In goat herds, government restrictions combined with vaccination are used to control paratuberculosis. From 1967 to 2001, goats were vaccinated with a live attenuated vaccine (Saxegaard and Fodstad, 1985), but from October 2001, inactivated vaccine (García Marín et al., 1999) has been used. Djønne et al. (2005) tested genotypic variation of MAP isolated from goats and cattle in Norway. They concluded that no genotypic variation existed that could be explained by different 
host origin and that the most common MAP isolates in Norway may infect both cattle and goats. In counties where vaccination has been compulsory, asymptomatic vaccinated goats still shed MAP in their feces (Djønne, 2003; Lybeck et al., 2011). Counties where MAP vaccination of goats is mandatory were used as a risk indicator because vaccination was mandatory only in counties where MAP was endemic. Hence, there was a higher probability in these areas for cattle to be exposed to MAP by infected goats.

Purchase. Three variables were constructed: import of cattle, purchase of cattle from counties where goats are vaccinated, and purchase of cattle from counties where goats are not vaccinated. Purchase data were obtained from NDHRS, and information regarding the vaccination program was collected from the Norwegian Goat Health Service. Infection with MAP is most commonly transmitted via feces, contaminated milk, or colostrum and fecal-contaminated feed (Sweeney, 1996). Sporadic fecal shedding of MAP has previously been reported in experimentally infected calves younger than 8 mo of age (McDonald et al., 1999). Others have suggested that naturally infected calves might shed MAP in feces intermittently and possibly in numbers below the detection limits of conventional methods (Whitlock and Buergelt, 1996; Antognoli et al., 2007). Antognoli et al. (2007) found that approximately $3 \%$ of naturally exposed calves were shedding MAP in feces at 8 mo of age. Therefore, calves and young stock were included in the purchase variable because they could be infected with MAP. The data were summarized at the herd level and adjusted for number of cow-years in the herd, which was calculated as the total number of lactating cows in the herd during a year.

Combined Cattle and Goat Farming. Because some of the diagnosed MAP-positive cattle in Norway have been linked to MAP-infected goat herds, close contact with goats was considered a potential risk factor. Data regarding combined cattle and goat farming were obtained from the Register of Production Subsidies, and this factor was categorized as a dichotomous variable.

Location of Cattle Farms. Given that caprine MAP is considered a risk factor for cattle in Norway, location of cattle farms in relation to infected goat farms was also considered to be a risk factor. Nielsen and Toft (2009) concluded that environmental contamination with MAP is a primary source of infection for dairy cattle. Smith et al. (2011) determined that environmental contamination with MAP was significantly correlated with MAP shedding levels in individual animals. Shared use of pasture in the mountains or near farms, together with shared use of manure equipment, may be considered risk factors for cattle acquiring MAP infection in Norway. Data on geographical location of cattle farms was obtained from NDHRS, and data regarding counties with mandatory caprine MAP vaccination strategies was obtained from the Norwegian Goat Health Service. Both variables were categorized as binominal.

\section{Risk Indicators}

Culling. Dairy cattle infected with MAP are usually culled prematurely (Wilson et al., 1995; Tiwari et al., 2005; Smith et al., 2010). Data on culling were collected from the NDHRS, and the derived variable included number of culled animals $>3 \mathrm{yr}$ of age adjusted for cow-years in the herd.

Decreased Milk Production. Infection with MAP can result in decreased milk production, but discrepancies are reported regarding which lactations exhibit the largest decrease (Nordlund et al., 1996; Hendrick et al., 2005; Beaudeau et al., 2007; Gonda et al., 2007; Tiwari et al., 2007; Sorge et al., 2011). Milk production decrease was divided into 2 variables: a decrease from the second to third lactations was the first variable, and a decrease from third to fourth, fourth to fifth, or fifth to sixth lactation was included as a second variable. A milk decrease is defined as the decrease in total volume ( $\mathrm{kg}$ of milk) from the previous lactation to the current lactation summarized for all cows in the herd. Positive changes in lactations are disregarded, whereas any negative changes are totaled and divided by the total cow-years of the herd. Heifers were not included because herd production performance and longevity were not impaired in MAP-infected heifers (Pillars et al., 2011). Around 18,000,000 milk production records were retrieved, including monthly or every-second-month milk controls, total kilograms of milk per lactation, DIM, and lactation number. To exclude improbable values for the milk production-related variables, the 99th percentile was used as a cut-off limit. Hence, all lactations that had a calving interval $>662 \mathrm{~d}$, produced $>12,300$ $\mathrm{kg}$ of milk, or had more than 442 DIM were excluded. All lactations without test-day registrations were also excluded. A decrease in total milk production was set as a continuous variable, where herds with the largest milk decreases were at higher risk than herds with lower or no milk decrease. The variable was adjusted for cowyears. Adjusting for SCC was not performed because of discrepancies regarding the association between SCC and MAP. Baptista et al. (2008) identified a strong association between high SCC and MAP antibodies but found no causal relationship. In contrast, others (Nordlund et al., 1996; Hendrick et al., 2005; Lombard et al., 2005; Gonda et al., 2007) found no significant differences between MAP-positive and MAP-negative cows in lactation mean linear SCC scores. 
Reduced Slaughter Condition. Weight loss resulting from MAP infection is typically referred to as lower or reduced slaughter value (Whitlock and Buergelt, 1996; Manning and Collins, 2001; McKenna et al., 2006). In Norway, the EUROP grid method of carcass classification is used to ensure the uniform classification of the carcasses of adult bovine animals (European Economic Community, 1988a,b; Regulations No. 1208/81 and No. 2930/81). The EUROP scheme is used to assess each carcass at the weighing point on the slaughter line. Carcass classification is performed subjectively by trained classifiers. The carcass classification is based on the EUROP scheme consisting of 5 meat conformation classes, where $\mathrm{E}$ is the highest class and $\mathrm{P}$ is the lowest class and represents little or no meat conformation (Animalia, 2011). The P class (like all EUROP classes) is further divided into 3 subclasses: $\mathrm{P}-, \mathrm{P}$, and $\mathrm{P}+$. In addition, the amount of fat on the outside of the carcass and in the thoracic cavity is described using 5 carcass fat classes, represented by the numbers 1,2 , 3,4 , and 5 , where 1 represents little or no fat in the thorax cavity. Each fat class is also further divided into 3 subclasses: $1-, 1$, and $1+$. Animalia is responsible for training and certifying all classifiers and for evaluating the different abattoir classifications.

Because MAP infection leads to emaciation and reduced slaughter condition, identification of slaughtered animals $>3$ yr of age that had been classified as having low conformation and no or little fat was considered a risk indicator for MAP. Carcasses that achieved conformation class $<\mathrm{P}+$ and fat class $<1+$ were considered at risk. Reduced slaughter condition was set as a continuous variable; hence, herds with registered emaciated animals were considered to have a higher probability of having MAP-infected cattle compared with herds with no emaciated animals. The variable was adjusted for cow-years by dividing the number of emaciated cows by the cow-years.

The proportions of carcasses with conformation class $<\mathrm{P}+$ and fat class $<1+$ differed among abattoirs. Assuming little geographical variation in slaughter conditions in the cattle population, the number of mature animals in conformation class $<\mathrm{P}+$ and fat class $<1+$ per herd was adjusted by weighting this value with the proportion of animals in this category at the abattoir in which the animals had been slaughtered. To avoid large differences in estimates for small abattoirs arising from casual variation (i.e., that arising from random variation caused by small sample size), abattoirs with fewer than 100 registered classifications were assumed to have proportions of $<1+$ and $<\mathrm{P}+$ equal to the mean of the larger abattoirs.

Diarrhea and Enteritis. Infection with MAP causes chronic infectious enteritis in domestic and wild ruminants. The physiological mechanism for diarrhea development in clinically affected animals is related to antigen-antibody reactions in infected tissue, with subsequent histamine release (Bendixsen, 1978). In Norway, all veterinarians have to record, describe, and sign off on all diagnoses and treatments of each dairy cow on an individual health card at the time of the visit. Here, all health card registrations on diarrhea and enteritis in animals $>3 \mathrm{yr}$ of age were included. The number of diarrhea registrations was included as a continuous variable and adjusted for cow-years.

Diarrhea is probably underreported in the NDHRS because it is only mandatory to report diseases that are treated by a veterinarian and diarrhea might be a condition that farmers treat themselves or do not treat at all. In a surveillance system based on veterinary reporting, some loss of events will occur because of the farmer's ability to detect diseases and treat milder cases without veterinary care. Some farmers also have a higher threshold for calling a veterinarian for help. This possibility was compensated for by including the days since the last disease registration in the herd as a variable in the model. This variable was not adjusted for cow-years to emphasize the severity of not reporting health events for large herds, given that naturally occurring health events should be more frequent in large herds than in small ones. If no registrations were found, the number of days equaled the study period.

\section{Statistical Analyses}

Data management and statistical analyses were performed using SAS for Windows (version 9.1.3; SAS Institute Inc., Cary, NC), Stata (version 10; StataCorp, College Station, TX), and R 2.15.1 (R Core Team, 2012). An R-package was developed for the MSPC analysis and can be provided upon request (solve. sabo@nmbu.no).

Most of the database entries used in this paper were manually registered; thus, some records are expected to contain human errors in addition to instrumental errors and randomly occurring extreme events. To limit the effect of these events, constraints on some of the recorded variables were enforced. All events with obvious errors were removed, including dates in the future, health records predating the birth of the animal, and lactation records with obvious errors in calving intervals and yield (e.g., extra digit during registration). The constraints removed around $4.9 \%$ of the milk records and $<30$ of the health records.

Time Variance of the Risk Indicators. All data in the databases are registered per individual animal with time resolved to dates. The derived risk indicators for this analysis were accumulated for $2 \mathrm{yr}$ per herd 
because of the slowly developing nature of MAP. This accumulation was achieved by summarizing all events from a given date and back $2 \mathrm{yr}$, and then moving the time window by $1 \mathrm{mo}$, thus giving overlapping 2 -yr windows in 23 of the 24 mo (Figure 2). To assess the effect of time variance and evaluate the different time windows needed to capture a change in the included variables, the model was run 3 times with 3 different time windows, moving the time window every year, every month, or every $15 \mathrm{~d}$. Principal component analysis (Pearson, 1901; Johnson and Wichern, 2002) was used on the 3 different time window data sets to evaluate changes in the variables over time.

Multivariate Statistical Process Control. Multivariate statistical process control is the multivariate counterpart of statistical process control (Shewhart, 1931; Ryan, 2011). The latter is used to monitor, for example, industrial processes, manufacturing of goods, and states of production plants. It is also applied in surveillance, especially in human disease monitoring and more generally in biosurveillance (Fricker, 2010). The many versions of MSPC employ various control charts for detecting outliers, drifts in mean values, and other properties of the process. In our context, the purpose of using process control was to detect a change in the risk factors that might indicate the occurrence of MAP. Because of the many potential risk factors and risk indicators for the disease, MSPC was used, which can take more than one variable into account. To build an MSPC model, a data set is required comprising time series of the risk factors in a disease-free period. Norway was not disease free during the study period, but if the amount of data is large, as in our study, and the prevalence of the disease is very low, the few cases will have only a negligible influence on the estimates of the model parameters.

The risk factors and risk indicators and how they are derived are described above. For the calculations, let $\mathbf{x}_{i j}$ denote a vector of $p$ risk indicators observed for herd $i$ at time point $j$. To say whether the observation should indicate an elevated chance of MAP for this herd at the given time, the difference between the observation and the expected values for the risk indicators under disease-free conditions must be estimated. A multivariate measure of distance (difference) that also takes into account the variance of and covariance between the risk indicators is the Hotelling's $\mathrm{T}^{2}$ statistic (Hotelling, 1931).

In the Hotelling's $\mathrm{T}^{2}$ statistic, let $\hat{\boldsymbol{\mu}}_{0}$ be the vector of means $(p \times 1)$ of the risk indicators computed from a (preferably) large number $n$ samples under disease-free conditions, and let $\hat{\boldsymbol{\Sigma}}$ be the $(p \times p)$ covariance matrix estimated from the same data. The Hotelling's $\mathrm{T}^{2}$ statistic for the observed value $\mathbf{x}_{i j}$, denoted $t^{2}$, is then computed as the sum of squared deviation from the mean of all variables, weighted by the estimated covariance matrix:

$$
t^{2}=n\left(\mathbf{x}_{i j}-\hat{\boldsymbol{\mu}}_{0}\right)^{\prime} \hat{\boldsymbol{\Sigma}}^{-1}\left(\mathbf{x}_{i j}-\hat{\boldsymbol{\mu}}_{0}\right) .
$$

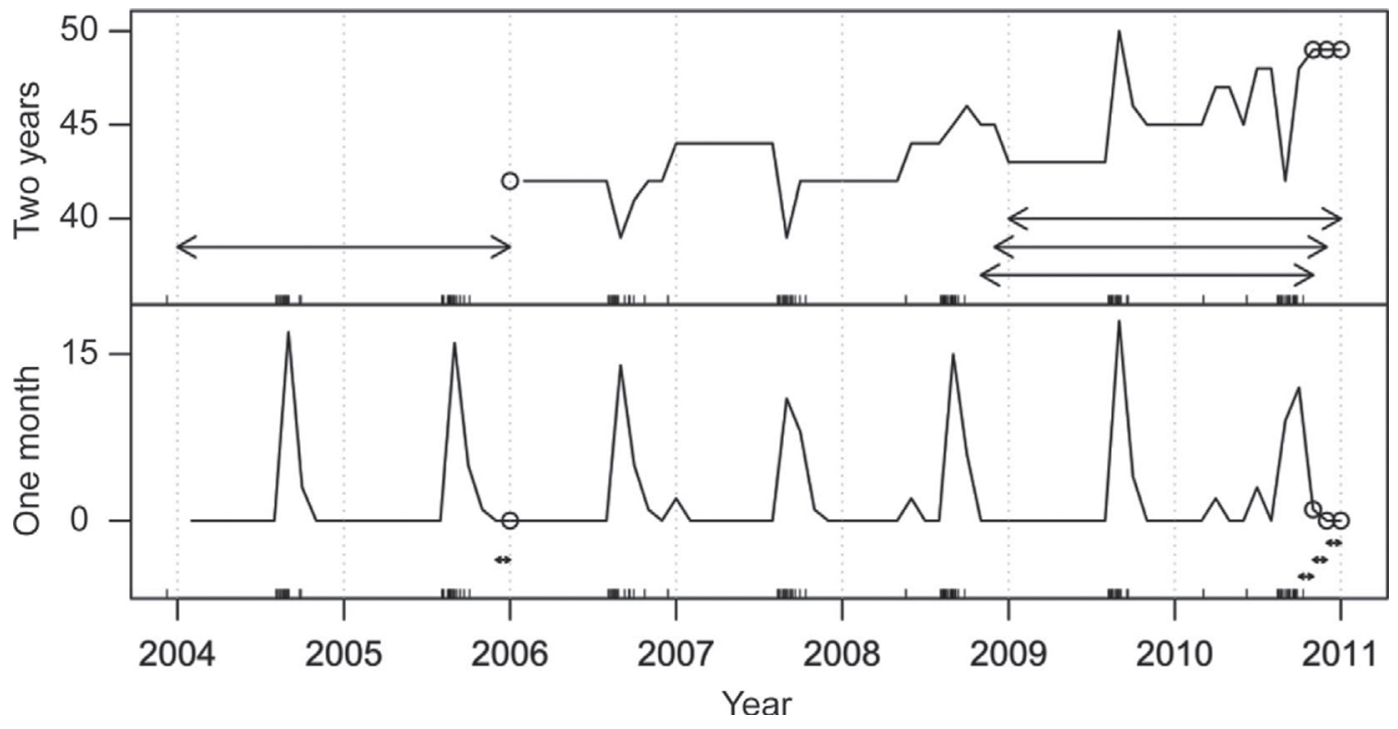

Figure 2. The figure shows how risk factor values are aggregated over time using a moving window of a chosen width, here with the number of purchased cattle at a randomly chosen farm as an example. The upper panel shows the aggregated curve using a 2-yr window, whereas the lower panel displays the corresponding curve based on a 1-mo window. At 4 time points (marked with circles), the corresponding window over which the value was aggregated is shown by a double-pointed arrow underneath. The "rugs" under the arrows show the actual dates the cattle entered the herd. 
Using $\hat{\boldsymbol{\Sigma}}^{-1}$ means that deviations in directions of little variation will contribute to the Hotelling's $T^{2}$ statistic equally to deviations in directions of large variation. Herds with a large value for Hotelling's $\mathrm{T}^{2}$ will have unusual values for one or several of the risk factors and should be flagged as potential MAP occurrences.

Because the risk indicators had low inter-correlations, no compression of the data was needed before MSPC was conducted. However, principal component analysis was used for another purpose here; namely, to explore the covariance structure of the risk factors and risk indicators and to see if the covariance structure depended on the width of the time windows used to aggregate the risk indicators, as mentioned in the previous section. A time period with test data was then included in the surveillance (e.g., the last month of the study period) in this analysis. For the test data, $\mathrm{t}^{2}$ values were calculated for all herds and ranked according to their score. Because the Hotelling's $\mathrm{T}^{2}$ statistic centers and standardizes, any standardizing or weighting of variables for which a common weight is used on all values in the variable will not affect the ranking.

\section{RESULTS}

The study included 3,044,262 animals (calves, young stock, and dairy cows) originating from 10,717 dairy herds from all over Norway. Most of the cattle were of the Norwegian Red breed (91.8\%) or Norwegian Red crossbreeds (5.6\%). The remaining cows were HolsteinFriesian, Jersey, and traditional Norwegian breeds. Table 1 shows the results of the descriptive analysis of risk factors and risk indicators.

\section{Risk Factors}

In total, 1,307 farms did not purchase any animals during the study period. Of the included animals, 494,458 (16.2\%) had been purchased within Norway during the study period. Of the 10,717 herds, 5,311 (49.6\%) included animals purchased from counties in which goats had been vaccinated, and 468 (4.4\%) farms had combined cattle and goat farming. A total of $4,774(44.5 \%)$ of the cattle farms were situated in MAP-vaccinated counties.

Cattle import almost completely ceased after 1996, being replaced by import of semen and embryos. During the study period, a total of 66 cattle were imported (Animalia, 2012). These were beef cattle and nonNDHRS members and therefore not included in our study. Imported cattle have to undergo an extended testing regimen (European Commission, 1988), and imported live cattle, semen, and embryos undergo ad-

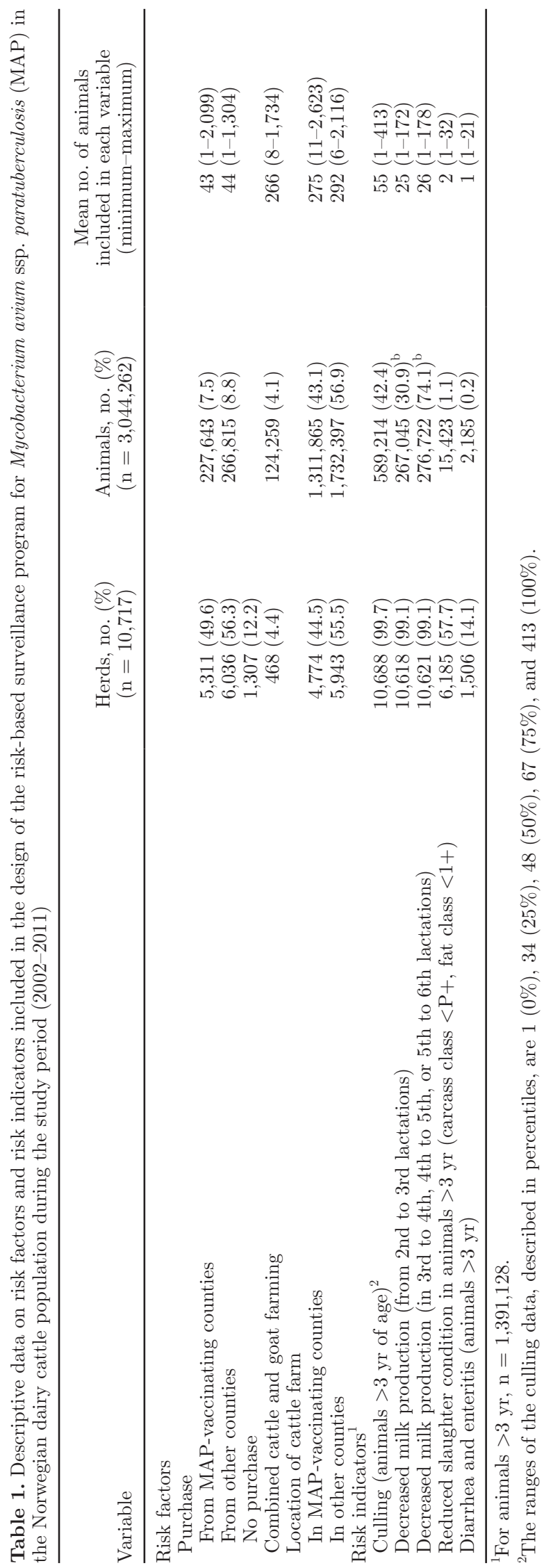

Journal of Dairy Science Vol. 97 No. 11, 2014 
ditional testing in accordance with the cattle industry's own requirements, handled by the Norwegian Livestock Industry's Biosecurity Unit (KOORIMP). Nevertheless, import of cattle is considered a risk factor that may be included when selecting herds in a future surveillance program for MAP.

\section{Risk Indicators}

A total of 1,391,128 individuals were $>3$ yr of age, and $589,214(42.3 \%)$ of these were culled during the study period (Table 1). A total of 1,750,770 individuals were culled during the study period, and $33.7 \%$ were animals $>3 \mathrm{yr}$ of age. The ranges of the culling data, described in percentiles, were $1(0 \%), 34(25 \%), 48$ (50\%), 67 (75\%), and 413 (100\%). In total, 895,955 lactating animals were registered, with 2,041,986 lactations. Overall, 267,045 (29.8\%) cows produced less milk in the third compared with the second lactation, and $276,722(30.9 \%)$ cows had any milk decrease from the third to fourth, fourth to fifth, or fifth to sixth lactations during the study period.

In total, 6,185 herds $(57.7 \%)$ had at least 1 carcass classified as $<\mathrm{P}+$ with fat class of $<1+$, and 15,423 $(1.1 \%)$ of the carcasses of animals $>3 \mathrm{yr}$ of age were classified as $<\mathrm{P}+$ with fat class of $<1+$. The percentage of slaughtered animals classified as $<\mathrm{P}+$ and $<1+$ varied from 0.6 to $9.7 \%$ per abattoir, and smaller abattoirs exhibited larger variation than larger abattoirs.

Diarrhea or enteritis in animals $>3$ yr of age was registered in 2,185 animals of 1,506 herds during the study period.

\section{Statistical Analyses}

Hotelling's $\mathrm{T}^{2}$ values for each farm for all months during the study period were calculated. The $\mathrm{t}^{2}$ (observed $\mathrm{T}^{2}$ ) values from the last month of the data set were plotted to show the geographical distribution of the estimated risk. High-risk areas were scattered all over Norway (Figure 3), both in counties with and without caprine MAP vaccination. Risk factors and risk indicators for the highest-ranking farms according to $t^{2}$ values are shown in Table 2 .

The principal component analysis revealed that moving the time window every month or every year had little effect on the covariance structure of the risk factors and risk indicators in the analysis. In Figure 2, the number of purchased cattle was accumulated over 2 yr and 1 mo, respectively. In Figure 2, negative peaks when periodic events had a negative trend and positive peaks when periodic events had a positive trend are observed. This pattern can arise when the 2-yr window gains a large contribution in the new (right) end and loses a large contribution in the old (left) end almost simultaneously.

Because the variables did not change much over time, the time window was moved every month, which coincided well with the frequency with which data were reported from the farms and abattoirs. This 1-mo interval gave feedback often enough to show progress in the monitored variables. Contribution from combinations of several risk factors and risk indicators was needed to yield a high-risk status. This requirement is evident from the density plots in Table 2, illustrating that the highest values for each risk variable are not represented among the highest-ranked farms.

\section{DISCUSSION}

To our knowledge, this report is the first description of a risk-based surveillance program that combines risk factors with risk indicators derived from production and clinical data. The success of a risk-based surveillance system depends on the choice of included factors and how these factors are processed in the analysis. This study presents a procedure that can improve the selection of herds in a risk-based surveillance program for MAP in Norway. By using MSPC, risk factors and risk indicators were extracted from different databases and combined to provide a quantitative risk assessment for each herd. In this way, risk-based surveillance using the extensive information in several national databases can be designed (Stärk et al., 2006). This approach contrasts with non-risk-based random sampling among all herds, in which the probability of finding MAP by chance is low because of the very low prevalence in the Norwegian population. When applying MSPC in risk-based surveillance programs, both single herds and geographical areas of elevated risk can be included in the control program.

The results of the analysis depend on the risk factors and risk indicators chosen for inclusion in the MSPC and how they are handled. The data used in the MSPC are skewed, but this skewing will have no effect on the ranking of the herds. The normality assumption has its implications when it comes to setting control limits according to the F-distribution of the Hotelling's statistic, but for our purpose of ranking herds, no control limits are needed and the normality assumption is in fact not needed. The variables had an equal opportunity to contribute to the variation in the model and to the final risk assessment. In addition, to contribute to a high $t^{2}$ value, a variable having much variation will need a relatively more-extreme event compared with a variable of little variation. Historically in Norway, association with a goat farm is considered a high risk, but because this factor is weighted the same as all other 


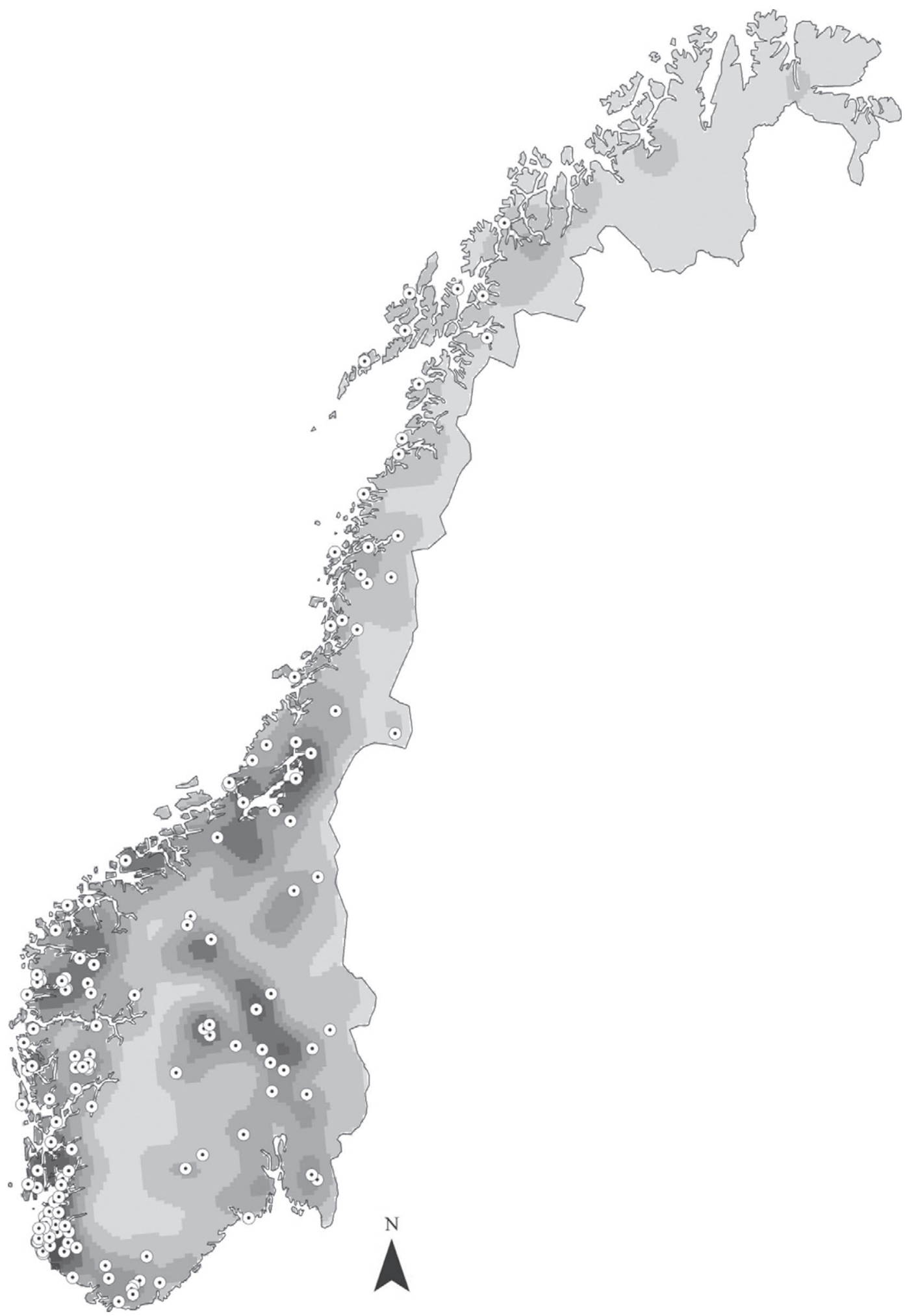

Figure 3. Map of Norway where the $\mathrm{t}^{2}$ (observed $\mathrm{T}^{2}$ ) values from the last month of the data set are plotted to show the geographical distribution of the 150 farms (indicated with black dots) having the highest estimated risk at the start of 2012. The background colors indicate the kernel density of dairy farms ranging from low density (light gray) to high density (dark gray). 
WHIST ET AL.

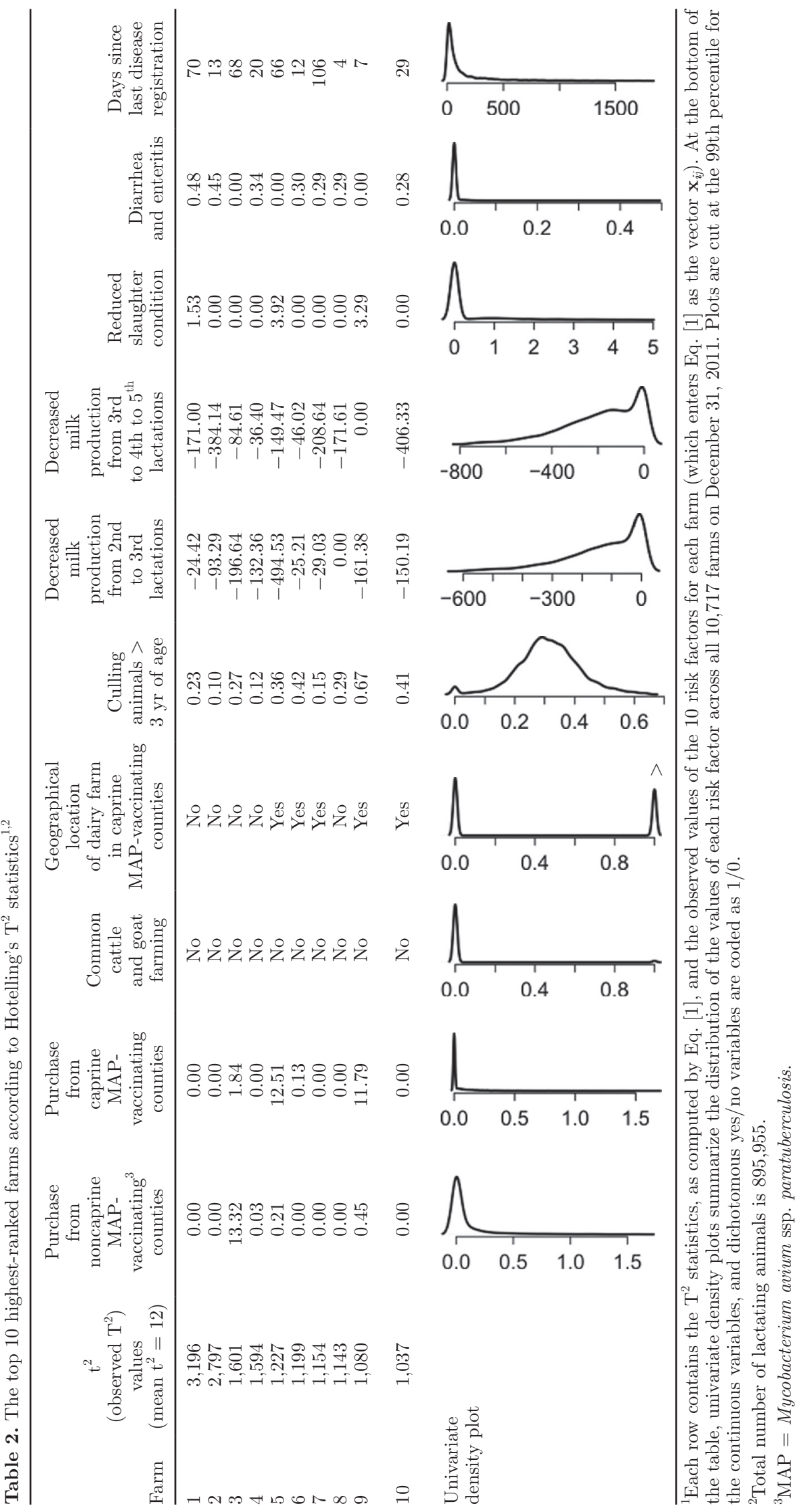


risks, it does not seem to figure prominently among the top 10 herds by Hotelling's $\mathrm{T}^{2}$ statistic (Table 2). Other, more-extreme values from the other risk indicators moved these herds to the top 10 list. Common cattle and goat farming was present in only $4.4 \%$ of the farms, whereas the 10 highest-ranked herds included only $0.1 \%$ of the farms. If the list were expanded to include 50 herds, 5 herds with common cattle and goat farming would be included, and if the list were further extended to the top $500,>50 \%$ of the common goat and cattle farms would be included.

Analysis of multiple data sources is becoming more feasible as data are more easily available electronically. The use of MSPC was suggested by Deming (1942) for disease surveillance and monitoring of rare events. Other more recent but less intuitive multivariate control chart statistics are also used in surveillance; for example, multivariate cumulative sum (MCUSUM) and multivariate exponentially weighted moving average (MEWMA; Fricker et al., 2008; Dubrawski, 2011), but these methods are more complex to work with, and we chose to work with MSPC. Buckeridge et al. (2005) concluded that an approach to conducting simultaneous analysis of multiple data sources is to use MSPC methods that explicitly account for the covariance among data sources. They found that MSPC methods tended to have greater sensitivity than univariate methods but that the MSPC methods also produced more false alarms. A modified version of the Hotelling's $\mathrm{T}^{2}$ statistic (Ye et al., 2000) can avoid this oversensitivity to some extent, and future research on directional adaptations of the newer methods seems warranted

No screening for MAP in the dairy population in Norway has been conducted, and no results are available that could have been used to validate and optimize the model. With the expected low prevalence of MAP in the Norwegian population and low specificity of serological tests for MAP, a high proportion of false positives would be expected. Therefore, the result of a survey would not be sufficiently precise to validate or reject the model. The risk indicators included in the model are based on factors associated with MAP in Norwegian cattle herds or on factors previously reported as risk factors for MAP. Herds selected based on these risk indicators are expected to have a higher probability of being infected with MAP. Although a quantitative estimate of the increase in sensitivity of the surveillance program has not been made, the improvements are assumed to be cost efficient because the cost of applying the method is low as soon as the system is established.

In the current surveillance program for MAP, the requirement of using bacteriology to obtain $100 \%$ specificity as well as economic constraints limited the number of annually examined dairy herds to 25. A dairy herd may yield high values for risk factors and risk indicators for several reasons. Using multivariate analysis should increase the specificity of the selection and, with the expected low prevalence of MAP in Norway dairy herds, obtaining a high rank for other reasons should be expected. Therefore, an increase in the number of herds examined is probably necessary to realize the full potential of using MSPC selection. Consequently, there is a need for specific tests suitable for screening purposes and validated on the Norwegian population. This need is in agreement with a study on the Swedish surveillance program for MAP, whose authors concluded that intensification of current activities or new surveillance activities are needed and that all the surveillance activities would benefit from improved diagnostic methods (Frössling et al., 2013). Jayarao et al. (2004) suggested that the IS900 PCR assay for MAP using bulk tank milk may not be useful for screening herds with MAP-infected animals. Timms et al. (2011) reviewed the sensitivity and specificity of different techniques for detecting MAP and concluded that development of more accurate and sensitive PCR assays is warranted. Thus, further research is needed into optimal diagnostic and sampling combinations to identify MAP-positive herds and avoid false-negative results, especially in groups of animals where the prevalence of MAP is expected to be low. Implementation of a risk-based surveillance in Norway will, at least theoretically, increase the prevalence of MAP-positive herds, and the rate of false-negative MAP herds will be reduced.

Making the development of diagnostic tests even more complex, differences in immune response may exist in different cattle breeds. Verschoor et al. (2010) suggested a mixed pro- and antiinflammatory phenotype from MAP-infected compared with healthy control animals and inherently different levels of immune and inflammatory-related gene expression between MAPinfected Holsteins and Jerseys. Woodbine et al. (2009) also found a significantly higher seroprevalence of MAP in dairy breeds, especially Jersey, compared with suckler breeds. They also found that smaller dairy herds $(<100$ cattle) had a relatively lower seroprevalence of MAP than dairy herds with $>99$ cattle. Infection with MAP was considered to be a clinical problem in the Norwegian cattle population during the first part of the 20th century. Different local cattle breeds made up the cattle population in Norway at that time. Since 1970, the predominant breed has become the Norwegian Red, which is a mix of different breeds. Thus, one can speculate that the Norwegian Red is more resistant to clinical infection with MAP than the local cattle breeds. The average herd size in Norway is 23 cow- 
years, which could also lower the seroprevalence, and hence MAP could be more difficult to detect.

Infection of a herd with MAP is a dynamic process in which infection status depends on many factors, including the number of animals shedding bacteria and the management conditions. Calculations and evaluation regarding how fast the risk-based surveillance program would detect a MAP outbreak have not been conducted but will be after some years of running the program. Because MAP is a slowly developing disease and the sensitivity of the diagnostic tests is poor, it is difficult to detect an early presence of the disease. Thus, a riskbased surveillance program could identify herds with an assumed higher risk of having MAP, and different tests could be performed in these herds.

National cattle production databases, where all production-related and health data on dairy cattle in the country are registered, are found in the Nordic countries, in Israel (Israeli Herdbook), and to some extent in Canada (Koeck et al., 2012). These databases provide farmers with useful multidisciplinary information, management analysis, and decision-making processes, and they are valuable resources in epidemiological research (Valde et al., 2004; Østerås et al., 2007). The collation of data from several sources can result in missing values, imprecise data, errors, and a large number of variables having nonlinear dependency structures. Databases constructed directly for research purposes are often referred to as primary research databases, whereas those originally constructed for other purposes are referred to as secondary databases (Sørensen et al., 1996). All databases mentioned in this paper are considered secondary databases because they were created for several different purposes and are subject to different practical and economic constraints. The interpretation and usefulness of data from secondary databases may be limited for research or surveillance purposes; hence, secondary databases must be validated (Lawrenson et al., 1999; Olsson et al., 2001; Mörk et al., 2009, 2010). Only a few examples exist in veterinary medicine in which the correctness and the completeness of databases have been evaluated (Nødtvedt et al., 2006; Mörk et al., 2009, 2010). The NDHRS has been validated for use in studies of calf diseases, locomotion disorders, clinical mastitis, and metabolic disease. Overall, it is considered (Gulliksen et al., 2009; Espetvedt et al., 2012; Lind et al., 2012; Wolff et al., 2012) that all studied diseases are underreported and therefore underestimated. It is therefore likely that diarrhea and enteritis were underreported in our data, potentially leading to lower risk scores for herds that actually have more prevalent diarrhea and enteritis.

Several factors could underlie the low completeness. One is that it is not mandatory to record diseases that are not treated by a veterinarian, and diarrhea is an example of a disease that farmers might treat themselves. Another reason could be that some farmers have a higher threshold for calling a veterinarian for help in general. The use and handling of diarrhea in a risk-based surveillance program is therefore an important issue to consider before deploying the procedure in real life. In an effort to reduce the underreporting problem, the days since the last clinical registration was included as a variable, which received high values if no diseases were reported on the farm. Because minor health-related incidents also occur quite frequently on healthy farms, high values for this variable will indicate a lack of reporting because of low priority or deliberate underreporting.

Dairy herds that did not report data to the NDHRS and beef cattle were not included in the analysis. Production and clinical data are more limited in these herds, and risk-based surveillance is therefore difficult to implement. The current national random surveillance program includes these herds. The main reasons for choosing dairy herds reporting data to the NDHRS were that data on dairy cattle were more complete and easily available and that introducing risk-based surveillance for MAP in dairy cattle might make it feasible to design more cost-efficient surveillance strategies, regardless of whether risk-based surveillance is also used for beef cattle.

The framework presented here is not limited to a particular infectious disease, and the surveillance program can be developed into syndrome surveillance programs in which one or several indicators would be routinely monitored for the early detection of emerging diseases. Madouasse et al. (2014) evaluated the use of regular monitoring of milk yield from herds to predict the emergence of 2007 bluetongue virus in France. They concluded that further research should be conducted on improving the prediction of test-day milk yield and on combining it with other indicators based on routinely collected data. In our study, a chronic disease was analyzed and the variables and interpretation chosen specifically for MAP. The frequency of updating the analysis (i.e., the moving of the time windows) had little effect on the risk factor relations results in a MAP analysis. However, adapting the procedure for early detection of acute infectious diseases might require changing the time frames for accumulation of data and updating the analysis sufficiently frequently.

\section{CONCLUSIONS}

To obtain an integrated and reliable valuation, multiple data sources were combined to make use of their complementary features. Given that the sampling 
density is maintained, the sampling of 50 herds selected using MSPC to identify herds with a higher probability of infection probably increases the surveillance sensitivity and should be at least equivalent to the current random selection. The use of MSPC for selection of herds would also be beneficial when a diagnostic test suited for mass screening and validated on the Norwegian population becomes available, making it possible to increase the number of sampled herds. Before initiating a new risk-based surveillance system for MAP, it is important to thoroughly analyze the data quality and the frequency of the events that are to be included. To some extent, a risk-based surveillance system will be unique for each specific population and will depend on the data sources, data quality, and normal frequency of the included variables.

\section{ACKNOWLEDGMENTS}

The authors gratefully acknowledge the use of data from Tine Norwegian Dairies, (Oslo, Norway; agreement number 01, 2010), Animalia Meat and Poultry Research Centre (Oslo, Norway), and The Norwegian Food Safety Authority (Oslo, Norway) for access to data. This study was funded by the Research Council of Norway, project number 199614/010.

\section{REFERENCES}

Animalia. 2011. Classification of cattle. Animalia, the Norwegian Meat and Poultry Research Centre, Norway (in Norwegian). Accessed Jan. 2, 2014. http://animalia.no/upload/Filer_fra_gammel_losning/ Filer\%20til\%20nedlasting/Klassifisering/INFORMASJON/Klass Storfe\% 202011\%20Web.pdf.

Animalia.2012.KOORIMP Annualreport(inNorwegian). AccessedJan.2, 2014. http://www.animalia.no/upload/FIler\%20til\%20nedlasting/ KOORIMP/KOORIMP\%20\%c3\%a5rsmelding\%202012\%20WEB. pdf.

Antognoli, M. C., H. L. Hirst, F. B. Garry, and M. D. Salman. 2007. Immune response to and faecal shedding of Mycobacterium avium ssp. paratuberculosis in young dairy calves, and the association between test results in the calves and the infection status of their dams. Zoonoses Public Health 54:152-159.

Baptista, F. M., S. S. Nielsen, and N. Toft. 2008. Association between the presence of antibodies to Mycobacterium avium subspecies paratuberculosis and somatic cell count. J. Dairy Sci. 91:109-118.

Beaudeau, F., M. Belliard, A. Joly, and H. Seegers. 2007. Reduction in milk yield associated with Mycobacterium avium subspecies paratuberculosis (Map) infection in dairy cows. Vet. Res. 38:625-634.

Bendixen, P. H. 1978. Immunological reactions caused by infection with Mycobacterium paratuberculosis: A review. Nord. Vet. Med. 30:163-168.

Buckeridge, D. L., H. Burkom, M. Campbell, W. R. Hogan, and A. W. Moore. 2005. Algorithms for rapid outbreak detection: A research synthesis. J. Biomed. Inform. 38:99-113.

Cameron, A. R. 2012. The consequences of risk-based surveillance: Developing output-based standards for surveillance to demonstrate freedom from disease. Prev. Vet. Med. 105:280-286.

Deming, W. E. 1942. On a classification of the problems of statistical inference. J. Am. Stat. Assoc. 37:173-185.

Djønne, B. 2003. Paratuberculosis in goats-A special focus on the Nordic countries. Acta Vet. Scand. 44:257-259.
Djønne, B., I. Pavlik, P. Svastova, M. Bartos, and G. Holstad. 2005. IS900 restriction fragment length polymorphism (RFLP) analysis of Mycobacterium avium ssp. paratuberculosis isolates from goats and cattle in Norway. Acta Vet. Scand. 46:13-18.

Dubrawski, A. 2011. Detection of events in multiple streams of surveillance data. Pages 145-171 in Infectious Disease Informatics and Biosurveillance. C. Castillo-Chavez, H. Chen, W. B. Lober, M. Thurmond, and D. Zeng, ed. Springer, New York, NY.

Espetvedt, M. N., C. Wolff, S. Rintakoski, A. K. Lind, and O. Østerås. 2012. Completeness of metabolic disease recordings in Nordic national databases for dairy cows. Prev. Vet. Med. 105:25-37.

European Commission. 1988. Council Directive 88/407/EEC of 14 June 1988: Laying down the animal health requirements applicable to intra-Community trade in and imports of deep-frozen semen of domestic animals of the bovine species. Off. J. L 194:10-23.

European Economic Community. 1981a. Regulations (EEC) No. 1208/81 of 28 April 1981 determining the Community scale for the classification of carcasses of adult bovine animals. Accepted Jan. 2, 2014. http://eur-lex.europa.eu/LexUriServ/LexUriServ.do?uri= CONSLEG:1981R1208:19910429:EN:PDF.

European Economic Community. 1981b. Regulations (EEC) and No. 2930/81 of 12 October 1981 adopting additional provisions for the application of the Community scale for the classification of carcasses of adult bovine animals. Accepted Jan. 2, 2014. http:// eur-lex.europa.eu/LexUriServ/LexUriServ.do?uri=CONSLEG:198 1R2930:19910730:EN:PDF.

Fredriksen, B., B. Djønne, Ó. Sigurð̋ardóttir, J. Tharaldsen, O. Nyberg, and J. Jarp. 2004. Factors affecting the herd level of antibodies against Mycobacterium avium subspecies paratuberculosis in dairy cattle. Vet. Rec. 154:522-526.

Fricker, R. D. 2011. Biosurveillance: Detecting, tracking, and mitigating the effects of natural disease and bioterrorism. Wiley Encyclopedia of Operations Research and Management Science. http:// dx.doi.org/10.1002/9780470400531.eorms1029.

Fricker, R. D., C. K. Matthew, and C. X. Hu. 2008. Comparing directionally sensitive MCUSUM and MEWMA procedures with application to biosurveillance. Qual. Eng. 20:478-494.

Frössling, J., H. Wahlström, E. C. C. Ågren, A. Cameron, A. Lindberg, and S. Sternberg Lewerin. 2013. Surveillance system sensitivities and probability of freedom from Mycobacterium avium ssp. paratuberculosis infection in Swedish cattle. Prev. Vet. Med. 108:47-62.

García Marín, J. F., J. Tellechea, M. Gutiérrez, J. M. Corpa, and V. Pérez. 1999. Evaluation of two vaccines (killed and attenuated) against small ruminant paratuberculosis. Pages 234-241 in Proc. Sixth Int. Colloq. Paratuberculosis. Melbourne, Australia. Int. Assoc. Paratuberculosis Inc., Providence, RI.

Gonda, M. G., Y. M. Chang, G. E. Shook, M. T. Collins, and B. W. Kirkpatrick. 2007. Effect of Mycobacterium paratuberculosis infection on production, reproduction, and health traits in US Holsteins. Prev. Vet. Med. 80:103-119.

Gulliksen, S. M., K. I. Lie, and O. Østerås. 2009. Calf health monitoring in Norwegian dairy herds. J. Dairy Sci. 92:1660-1669.

Hadorn, D. C., and K. D. Stärk. 2008. Evaluation and optimization of surveillance systems for rare and emerging infectious diseases. Vet. Res. 39:57.

Hendrick, S. H., D. F. Kelton, K. E. Leslie, K. D. Lissemore, M. Archambault, and T. E. Duffield. 2005. Effect of paratuberculosis on culling, milk production, and milk quality in dairy herds. J. Am. Vet. Med. Assoc. 227:1302-1308.

Hotelling, H. 1931. The generalization of Student's ratio. Ann. Math. Stat. 2:360-378.

Hotelling, H. 1947. Multivariate quality control, illustrated by the air testing of sample bombsights. Pages 111-184 in Selected Techniques of Statistical Analysis. C. Eisenhart, M. W. Hastay, and W. A. Wallis, ed. McGraw-Hill, New York, NY.

Jayarao, B. M., S. R. Pillai, D. R. Wolfgang, D. R. Griswold, C. A. Rossiter, D. Tewari, C. M. Burns, and L. J. Hutchinson. 2004. Evaluation of IS900-PCR assay for detection of Mycobacterium avium subspecies paratuberculosis infection in cattle using quarter milk and bulk tank milk samples. Foodborne Pathog. Dis. 1:17-26. 
Johnson, R. A., and D. W. Wichern. 2002. Applied Multivariate Statistical Analysis. 5th ed. Prentice-Hall, Upper Saddle River, NJ.

Kampen, A., B. Djønne, and P. Hopp. 2010. The surveillance and control programs for terrestrial and aquatic animals in Norway. Annual report, Norwegian Veterinary Institute. Accessed Feb. 2, 2014. http://www.vetinst.no/Publikasjoner/OK-rapporter/ NOK-2010/Paratuberkulose-2010.

Koeck, A., F. Miglior, D. F. Kelton, and F. S. Schenkel. 2012. Health recording in Canadian Holsteins: Data and genetic parameters. J. Dairy Sci. 95:4099-4108.

Lawrenson, R., T. Williams, and R. Herder. 1999. Clinical information for research; the use of general practice databases. J. Public Health Med. 21:299-304.

Lind, A., P. T. Thomsen, A. K. Ersbøll, M. N. Espetvedt, C. Wolff, S. Rintakoski, and H. Houe. 2012. Validation of Nordic dairy cattle disease recording databases-Completeness for locomotor disorders. Prev. Vet. Med. 107:204-213.

Lombard, J. E., F. B. Garry, B. J. McCluskey, and B. A. Wagner 2005. Risk of removal and effects on milk production associated with paratuberculosis status in dairy cows. J. Am. Vet. Med. Assoc. 227:1975-1981.

Lybeck, K. R., A. K. Storset, B. Djønne, M. Valheim, and I. Olsen 2011. Faecal shedding detected earlier than immune responses in goats naturally infected with Mycobacterium avium ssp. paratuberculosis. Res. Vet. Sci. 91:32-39.

Madouasse, A., A. Marceau, A. Lehébel, H. Brouwer-Middelesch, G. van Schaik, Y. Van der Stede, and C. Fourichon. 2014. Use of monthly collected milk yields for the detection of the emergence of the 2007 French BTV epizootic. Prev. Vet. Med. 113:484-491.

Manning, E. J., and M. T. Collins. 2001. Mycobacterium avium ssp. paratuberculosis: pathogen, pathogenesis and diagnosis. Rev. Sci. Tech. 20:133-150.

Martin, P. A., A. R. Cameron, K. Barfod, E. S. Sergeant, and M Greiner. 2007. Demonstrating freedom from disease using multiple complex data sources 2: Case study - Classical swine fever in Denmark. Prev. Vet. Med. 79:98-115.

McDonald, W. L., S. E. Ridge, A. F. Hope, and R. J. Condron. 1999. Evaluation of diagnostic tests for Johne's disease in young cattle. Aust. Vet. J. 77:113-119

McKenna, S. L., G. P. Keefe, A. Tiwari, J. VanLeeuwen, and H. W. Barkema. 2006. Johne's disease in Canada. Part II: Disease impacts, risk factors, and control programs for dairy producers. Can. Vet. J. 47:1089-1099.

Mörk, M. J., A. Lindberg, S. Alenius, I. Vågsholm, and A. Egenvall. 2009. Comparison between dairy cows diseases incidence in data registered by herders and in data from a disease-recording system based on veterinary reporting. Prev. Vet. Med. 88:298-307.

Mörk, M. J., C. Wolff, A. Lindberg, I. Vågsholm, and A. Egenvall. 2010. Validation of a national disease recording system for dairy cattle against veterinary practice records. Prev. Vet. Med. 93:183-192.

Nielsen, S. S., and N. Toft. 2009. A review of prevalences of paratuberculosis in farmed animals in Europe. Prev. Vet. Med. 88:1-14.

Nødtvedt, A., K. Bergvall, U. Emanuleson, and A. Egenvall. 2006. Canine atopic dermatitis; validation of recorded diagnosis against practice records in 335 insured Swedish dogs. Acta Vet. Scand. 48:8.

Nordlund, K. V., W. J. Goodger, J. Pelletier, and M. T. Collins. 1996. Associations between subclinical paratuberculosis and milk production, milk components, and somatic cell counts in dairy herds. J. Am. Vet. Med. Assoc. 208:1872-1876.

Olsson, S. O., P. Paekbo, S. O. Hansson, H. Rautala, and O. Østerås. 2001. Disease recording systems and herd health schemes for production diseases. Acta Vet. Scand. Suppl. 94:51-60.

Østerås, O., H. Solbu, A. O. Refsdal, T. Roalkvam, O. Filseth, and A. Minsaas. 2007. Results and evaluation of thirty years of health recordings in the Norwegian dairy cattle population. J. Dairy Sci. 90:4483-4497.

Paisley, L. G., J. Tharaldsen, and J. Jarp. 2000. A simulated surveillance program for bovine paratuberculosis in dairy herds in Norway. Prev. Vet. Med. 44:141-151.
Pearson, K. 1901. On lines and planes of closest fit to systems of points in space. Philos. Mag. 2:559-572

Pillars, R. B., M. W. Bolton, and D. L. Grooms. 2011. Case-control study: Productivity and longevity of dairy cows that tested positive for infection with Mycobacterium avium ssp. paratuberculosis as heifers compared to age-matched controls. J. Dairy Sci 94:2825-2831.

R Core Team. 2012. R: A language and environment for statistical computing. R Foundation for Statistical Computing, Vienna, Austria. Accessed Feb. 15, 2014. http://www.R-project.org/.

Ryan, T. P. 2011. Statistical Methods for Quality Improvement. 3rd ed. John Wiley \& Sons Inc., Hoboken, NJ.

Salman, M. D. 2003. Surveillance and monitoring systems for animal health programs and disease surveys. Pages 3-13 in Animal Disease Surveillance and Survey Systems. M. D. Salman, ed. Iowa State Press, Ames, IA

Saxegaard, F., and F. H. Fodstad. 1985. Control of paratuberculosis (Johne's disease) in goats by vaccination. Vet. Rec. 116:439-441.

Shewhart, W. A. 1931. Economic Control of Quality of Manufactured Product. Van Nostrand Company Inc., New York, NY.

Smith, R. L., Y. H. Schukken, A. K. Pradhan, J. M. Smith, R. H Whitlock, J. S. Van Kessel, D. R. Wolfgang, and Y. T. Grohn. 2011. Environmental contamination with Mycobacterium avium ssp. paratuberculosis in endemically infected dairy herds. Prev. Vet. Med. 102:1-9.

Smith, R. L., R. L. Strawderman, Y. H. Schukken, S. J. Wells, A. K Pradhan, L. A. Espejo, R. H. Whitlock, J. S. Van Kessel, J. M. Smith, D. R. Wolfgang, and Y. T. Gröhn. 2010. Effect of Johne's disease status on reproduction and culling in dairy cattle. J. Dairy Sci. 93:3513-3524.

Solbu, H. 1983. Disease recording in Norwegian dairy cattle. I. Disease incidences and non-genetic effects on mastitis, ketosis and milk fever. Z. Tierzucht. Zuchtungsbio. 100:139-157.

Sørensen, H. T., S. Sabroe, and J. Olsen. 1996. A framework for evaluation of secondary data sources for epidemiological research. Int J. Epidemiol. 25:435-442.

Sorge, U. S., K. Lissemore, A. Godkin, S. Hendrick, S. Wells, and D. Kelton. 2011. Associations between paratuberculosis milk ELISA result, milk production, and breed in Canadian dairy cows. J. Dairy Sci. 94:754-761.

Stärk, K. D., G. Regula, J. Hernandez, L. Knopf, K. Fuchs, R. S. Morris, and P. Davies. 2006. Concepts for risk-based surveillance in the field of veterinary medicine and veterinary public health: Review of current approaches. BMC Health Serv. Res. 6:20.

Sweeney, R. W. 1996. Transmission of paratuberculosis. Vet. Clin. North Am. Food Anim. Pract. 12:305-312.

Thrusfield, M. 2005. Determinants of Disease. 3rd ed. Blackwell Publ. Prof., Ames, IA.

Timms, V. J., M. M. Gehringer, H. M. Mitchell, G. Daskalopoulus, and B. A. Neilan. 2011. How accurately can we detect Mycobacterium avium ssp. paratuberculosis infection? J. Microbiol. Methods $85: 1-8$

Tine Rådgiving. 2011. Annual report (in Norwegian). Accessed Feb. 15, 2014. http://www.tine.no/om-tine/aktuelt-og-media/ arsrapporter/annual-reports.

Tiwari, A., J. A. VanLeeuwen, I. R. Dohoo, H. Stryhn, G. P. Keefe, and J. P. Haddad. 2005. Effects of seropositivity for bovine leukemia virus, bovine viral diarrhoea virus, Mycobacterium avium ssp. paratuberculosis, and Neospora caninum on culling in dairy cattle in four Canadian provinces. Vet. Microbiol. 109:147-158.

Tiwari, A. J. A. VanLeeuwen, J. P. Haddad, I. R. Dohoo, H. Stryhn, G. P. Keefe, H. M. Scott, and R. Tremblay. 2007. Production effects of pathogens causing bovine leukosis, bovine viral diarrhea, paratuberculosis, and neosporosis. J. Dairy Sci. 90:659-669.

Valde, J. P., L. G. Lawson, A. Lindberg, J. F. Agger, H. Saloniemi, and O. Osterås. 2004. Cumulative risk of bovine mastitis treatment in Denmark, Finland, Norway and Sweden. Acta Vet. Scand. 45:201-210.

Verschoor, C. P., S. D. Pant, Q. You, D. F. Kelton, and N. A. Karrow. 2010. Gene expression profiling of PBMCs from Holstein and 
Jersey cows subclinically infected with Mycobacterium avium ssp. paratuberculosis. Vet. Immunol. Immunopathol. 137:1-11.

Whitlock, R. H., and C. Buergelt. 1996. Preclinical and clinical manifestations of paratuberculosis (including pathology). Vet. Clin. North Am. Food Anim. Pract. 12:345-356.

Wilson, D. J., C. Rossiter, H. R. Han, and P. M. Sears. 1995. Financial effects of Mycobacterium paratuberculosis on mastitis, milk production, and cull rate in clinically normal cows. Agric. Pract. 16:12-18.

Wolff, C., M. Espetvedt, A. K. Lind, S. Rintakoski, A. Egenvall, A. Lindberg, and U. Emanuelson. 2012. Completeness of the disease recording systems for dairy cows in Denmark, Finland, Norway and Sweden with special reference to clinical mastitis. BMC Vet. Res. 8:131.

Woodbine, K. A., Y. H. Schukken, L. E. Green, A. Ramirez-Villaescusa, S. Mason, S. J. Moore, C. Bilbao, N. Swann, and G. F. Medley. 2009. Seroprevalence and epidemiological characteristics of Mycobacterium avium ssp. paratuberculosis on 114 cattle farms in south west England. Prev. Vet. Med. 89:102-109.

Ye, N., Q. Cheng, S. Emran, and S. Vilbert. 2000. Hotelling's T ${ }^{2}$ multivariate profiling for anomaly detection. In IEEE Workshop on Information Assurance and Security. IEEE, West Point, NY. 